\title{
Alpha-1 Microglobulin to Creatinine Ratio Measurement
}

National Cancer Institute

\section{Source}

National Cancer Institute. Alpha-1 Microglobulin to Creatinine Ratio Measurement. NCI

Thesaurus. Code C100462.

The determination of the ratio of alpha-1 microg lobulin compared to creatinine present in a sample. The measurement may be expressed as a ratio or percentage. 